\title{
PKMS PELATIHAN DESAIN GRAFIS MENUJU WIRAUSAHA BAGI PEMUDA RT.03 RW.04 KELURAHAN UMBAN SARI
}

\author{
Yenny Desnelita ${ }^{* 1}$, Gustientiedina $^{2}$, Wilda Susanti ${ }^{3}$, Dewi Nasien ${ }^{4}$, Ramalia Noratama Putri $^{5}$ \\ ${ }^{1,5}$ Program Studi Sistem Informasi, ${ }^{2,3,4}$ Program Studi Teknik Informatika, Sekolah Tinggi Ilmu \\ Komputer Pelita Indonesia \\ *E-mail: yenny.desnelita@lecturer.pelitaindonesia.ac.id
}

\begin{abstract}
The expansion of applications in the information technology field has a big impact in various fields of life, one of them is in the creative industries such as advertising, billboards, graphic design and digital image processing. One of the supporting skills for young people at RT 03 RW 04 Umban Sari, Rumbai district, Pekanbaru. It is conducted life skills training in the form of graphic design for advertising and billboards. This dedication method is in the form of training in graphic design skills using computers and using CorelDraw and Photoshop software. This PKMS activity aims to increase the knowledge and skills of youth in improving the quality of ability in making attractive graphic designs so that participants can compete to meet the demands for employment and also towards entrepreneurship. From 15 participants, 11 of them succeeded in making and completing designing products for advertising or printing needs. The results of the graphic design skills training activity show participants can design logos, business cards, invitations, famplets, banners, and other forms of advertising.
\end{abstract}

Keywords - Life skills, graphic design skills, young people, advertising.

\begin{abstract}
Abstrak
Perkembangan aplikasi di bidang teknologi informasi mempunyai dampak besar di berbagai bidang kehidupan, salah satunya dibidang industri kreatif seperti advertising, reklame, desain grafis dan pengolahan gambar digital. Salah satu menunjang keterampilan bagi pemudapemudi RT 03 RW 04 Kelurahan Umban Sari Kecamatan Rumbai Kota Pekanbaru. Dilakukan pelatihan life skill yang berupa perancangan desain grafis untuk advertising dan reklame. Metode pengabdian ini berupa pelatihan keterampilan desain grafis yang menggunakan computer dan memakai software CorelDraw dan Photoshop. Kegiatan PKMS ini bertujuan untuk meningkatkan pengetahuan dan keterampilan pemuda dalam meningkatkan kualitas kemampuan dalam membuat desain grafis yang menarik sehingga peserta dapat bersaing untuk memenuhi permintaan akan kebutuhan lapangan kerja dan juga menuju wirausaha. Dari 15 peserta 11 orang diantaranya berhasil membuat dan menyelesaikan mendesain produk untuk kebutuhan advertising atau bidang percetakan. Hasil kegiatan pelatihan keterampilan desain grafis menunjukan peserta bisa merancang logo, kartu nama, undangan, famplet, banner, spanduk dan bentuk advertising lainnya.
\end{abstract}

Kata kunci-Life skill, keterampilan desain grafis, pemuda-pemudi, advertising.

\section{PENDAHULUAN}

Bagian dari masyarakat yang paling produktif adalah generasi muda, dimana kemampuan atau potensi yang dimiliki oleh sebagian kaum muda tidak terlaksana secara optimal disebabkan kurang motivasi , arahan dan bimbingan. Kegiatan kaum muda hanya berkumpul yang tidak dapat menghasilkan suatu manfaat untuk diri para kaum muda itu sendiri supaya menjadi lebih produktif dalam keahlian untuk merajut masa depannya.

Diadakannya berbagai macam pelatihan dalam upaya kualitas dan peningkatan Sumber Daya Manusia (SDM) untuk pemberdayaan dan penanggulangan taraf hidup masyarakat oleh pemerintah atau lembaga-lembaga tertentu. Dalam peningkatan SDM dapat juga dilakukan melalui pemberian ilmu pengetahuan supaya masyarakat menjadi lebih terampil dalam berbagai hal. 
Hal ini memiliki dampak positif terhadap masyarakat, selain untuk memberikan ilmu pengetahuan juga adanya upaya agar masyarakat menjadi lebih terampil dalam berbagai hal. Peningkatan kualitas keterampilan, salah satunya adalah dengan pelatihan desain grafis, yang mempunyai tujuan dalam peningkatan SDM yang profesional (berkualitas) dan dapat bersaing memenuhi permintaan dunia industri, kebutuhan lapangan kerja dan berwirausaha (enterpreneur) seperti membuat usaha percetakan.

Perancangan grafis merupakan suatu bentuk komunikasi visual berupa gambar dan teks dalam menyampaikan pesan dan informasi. Aplikasi untuk perancangan grafis yang banyak dan populer digunakan adalah software coreldraw dan photoshop. Coreldrawdan Photoshop merupakan software desain grafis untuk pengolahan gambar yang disusun dari gabungan garis dan titik, dimana tergabung dalam unsur-unsur garis, ruang, warna dan tekstur membentuk aspek struktural dengan komposisi yang lebih luas dan prinsip-prinsip desain visual[1].Corel pencipta softwarecoreldraw yang berupa editor grafik vektor[2]. Software coreldraw dan photoshop mempunyai kemampuan kognitif, pengolahan gambar, keterampilan tipografi, dan page layout serta menggabungkan teks, gambar, animasi secara visual pada berbagai macam media publikasi dengan tool dan link bagi pengguna dalam bentuk navigasi yang dapat berintegrasi dan berkomunikasi[3].

RT 03 beradadidalamlingkungan RW04 KelurahanUmban Sari KecamatanRumbai Kota Pekanbarudimanatempat melakukan pengabdian kepada masyarakat yang salah satu kegiatannya berupa Pelatihan desain grafis menuju wirausaha menggunakan software coreldraw dan adopephotoshop untuk membuat produk advertising dan reklame yang diangkat dalam kegiatan pelatihan yang dilakukan oleh dosen dan mahasiswa Sekolah Tinggi Ilmu Komputer Pelita Indonesia pada pengabdian kepada masyarakat. Materi pelatihan tentang desain grafis seperti pembuatan banner, spanduk, brosur, famplet dan surat undangan disiapkan sedemikian rupa agar mudah dipelajari oleh peserta pelatihan, selain itu juga diberikan materi lengkap tentang tutorial sehingga peserta pelatihan dapat belajar dan mengulanginya sendiri maupun berkelompok tentang materi yang telah disampaikan.

Bentuk kegiatan pengabdian kepada masyrakat berupa pelatihan atau workshop, yakni bentuk kegiatan untuk mengeksplorasi ide dan memberikan pelatihan, dimana semua peserta pelatihan terlibat aktif, pemaparan materi dan memberikan pelatihan langsung beriupa praktek dengan menggunakan software coreldraw dan adobe photoshop. Diakhir pelatihan dilakukan simulasi dengan diskusi, tanya jawab dan praktek untuk mencetak hasil karya peserta pelatihan di percetakan Lunner Print yang sudah dilaksanakan. Software desain grafis dapat juga digunakan untuk membuat desain motif batik dalam kegiatan pengabdian penerapan IPTEKS batik training untuk siswa-siswi SMK Negeri 5 kota Bengkulu[4]. Dalam pengabdian masyarakat yang dilakukan oleh Graha et, al.,[5] untuk mewujudkan industri kreatif desain grafis yang berorientasi pada pelayanan konsumen dengan produk desain grafis non cetak yang personalized. Kegiatan pengabdian kepada masyarakat dalam penggunaan software adobe photoshop dan coreldraw dapat juga digunakan dalam fotografi untuk bisnis industri kreatif[6] dimana menurut susanto, dkk.,[7] media publikasi spanduk dan brosur dapat dibuat dengan menggunakan software adobe photoshop menjadi media publikasi yang menarik dan efektif.

Para pemuda yang memiliki keterampilan desain grafis dapat menyerap tenaga kerja, berwirausaha sehingga diharapkan bisa mengatasi masalah pengangguran bagi pemuda-pemudi di RT03 RW04 Kelurahan Umbang Sari Kecamatan Rumbai Kota Pekanbaru sebagai mitra pada kegiatan ini. Target yang dicapai dalam pelatihandesain grafis diharapkan peserta dapat mempunyai bekal yang cukup untuk membantu membuat wirausaha dan bekerja dalam dunia industri, pemerintahan dan organisasi-organisasi pada semua sektor yang ada. Dimana kewirausahaan sebagai faktor sosial ekonomi adalah faktor terpenting dari transformasi ekonomi masyarakat, dan pengaruhnya terhadap berbagai bidang hubungan sosial-ekonomi[8]. Praktik pelatihan profesional wirausaha berdasarkan bantuan teknologi pendamping akan meningkatkan pelatihan profesional dan menghasilkan hasil kegiatan mereka[9][10]. 


\section{METODE}

Metode pelaksanaan kegiatan PKMS ini menggunakan teknik-teknik dari metode pendidikan orang dewasa yaitu teknik ceramah, diskusi, demonstrasi, dan pelatihan. Metode pelatihan PKMS dilakukan sebagai berikut :

1. Metode ceramah: dalam metode ceramah dilakukan pemberian materi secara tatap muka dan lisan. Tujuan dari ceramah adalah pemberian informasi tentang desain grafis dan software coreldraw dan photoshop. Teknik yang dilakukan adalah penyuluhan dimana bertujuan memberikan pengertian dan pemahaman tentang desain grafis beserta software yang digunakan untuk membuat produk advertising, reklame dan produk lainnya, pemberian materi life skill (kecakapan hidup), manajemen usaha, serta kewirausahaan (enterpreneurship).

2. Metode Demonstrasi/Praktek: penyampaian teori beserta praktek dan demonstrasi yang merupakan kemampuan keterampilan (psikomotorik) penggunaan software coreldraw dan photoshop.

3. Diskusi: proses pemecahan masalah dengan memberikan umpan balik kepada peserta terhadap pemasalahan yang dihadapi dalam merancang produk advertising seperti membuat poster, spanduk, kartu undangan dan banner.

4. Implementasi: proses akhir peserta dapat mengimplementasikan produk advertising menggunakan desain grafis dengan software coreldraw dan photoshop melalui percetakan.

5. Evaluasi

Dalam tahap evaluasi ini proses pengukuran terhadap pelatihan dan implementasi pengunaan software coreldraw dan photoshop terhadap produk yang dibuat adalah a) tim pengabdi memantau mengerti atau tidaknya peserta serta mengukur keberhasilan pengabdian melalui penyebaran kuisioner sesudah diadakan pelatihan, b) mengevaluasi jadwal pelaksanaan kegiatan, alokasi waktu, materi kegiatan dan metode yang telah dilakukan.

\section{HASIL DAN PEMBAHASAN}

\subsection{Pelaksanaan Pelatihan Pembuatan Produk Advertising dan Reklame}

Kegiatan pengabdian ini dilaksanakan dalam bulan Juli sampai dengan Oktober 2019 bertempat dilaboratorium Sekolah Tinggi Ilmu Komputer Pelita Indonesia dan percetakan Lunner Printsebagai tempat pelatihan untuk mencetak produk menggunakan mesin percetakan dengan aktifitas kegiatan diantaranya adalah pelatihan pembuatan desain grafis menggunakan coreldraw dan photoshop untuk merancang produk-produk advertising dan reklame seperti banner, spanduk, brosur, kartu undangan, famplet dan produk lainnya.

Pemuda-pemudi RT. 03 RW. 04 Kelurahan Umban Sari yang merupakan peserta pelatihan desain grafis melakukan pelatihan dengan mendengarkan ceramah, melakukan tanya jawab dan praktek dari narasumber berjalan dengan lancar dan kondusif. Peserta dengan lugas, kreatif melakukan kegiatan pelatihan berupa praktek yang langsung di pandu oleh narasumber. Hasil pelatihan dapat identifikasi bahwa pengetahuan peserta tentang penggunaan software desain grafis yaitu coreldraw dan photoshop sebagian sudah dapat merancang produk-produk advertising, banner dan reklame dengan baik yang diikuti oleh 15 orang pemuda-pemudi dari RT 03Kel. Umabn Sari yang diilustrasikan pada gambar 1.

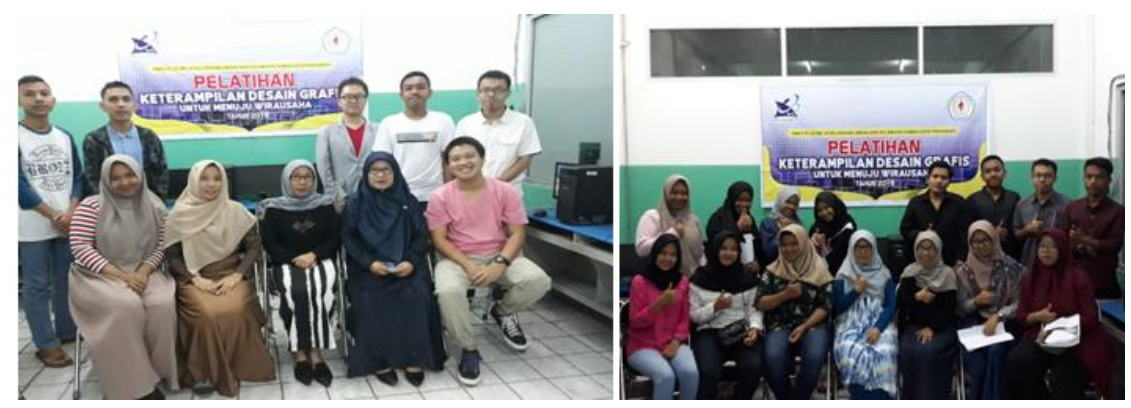

Gambar 1 Narasumber dan Peserta Kegiatan PKMS 
Kegiatan ini diadakan setiap hari sabtu dan minggu. Dengan rincian materi adalah perkenalan toolbox, membuat dan mendasain logo dari objek primitif, membuat logo dengan dari objek vektor, membuat gambar ilustrasi, desain kartu nama, desain kartu undangan, desain famplet desain spanduk dan sampai mencetak produk yang dibuat menggunakan coreldraw dan photoshop dengan langsung praktek. Salah satu software yang digunakan dapat mewujudkan komunikasi yang efektif antara peserta Pengabdian Kepada Masyarakat Stimulus dengan narasumber dalam membuat produk-produk advertasingdan reklame.

Materi yang disampaikan pada kegiatan PKMS ini adalah sebgai berikut:

1. Pengenalan coreldraw dan photoshop, disini diberikan penjelasan tentang fungsi dan kegunaan coreldraw dan photoshop.

2. Pengenalan tool dalam coreldraw dan photoshop

3. Praktek dengan membuat produk-produk advertising dan reklame

4. Praktek mencetak produk advertising dan reklame pada percetakan Lunner Print

Pada gambar 2 memperlihatkan kegiatan pelatihan yang diikuti oleh para peserta dari RT.03 RW.04 Kelurahan Umban Sari Kecamatan Rumbai Kota Pekanbaru. Pada kegiatan pelatihan, yang menjadi narasumber materi dilakukan oleh tim pelaksana PKMS yang terdiri dari dosen dan mahasiswa sebagai tim pembantu teknik pelaksanaan Pengabdian. Pelaksanaan PKMS ini dinyatakan berhasil dengan telah bisanya peserta membuat Produk advertising dan reklame seperti: benner, spanduk, famplet, kartu undangan, brosur dengan menggunakan software coreldraw dan photoshop. Pembuatan desain brosur, banner, poster dan stiker dengan menggunakan objek gambar yang dibentuk berdasarkan titik dan kombinasi warna (Grafis Bitmap) [11]. Sedangkan untuk mendesain logo bisa menggunakan beberapa aplikasi terbaru yang ada, diantaranya Quick Start, Table, Smart Drawing Tool, Save as Template dan lain sebagainya[12]. Kegiatan pelatihan dalam PKMS dapat diilustrasikan pada gambar 2.

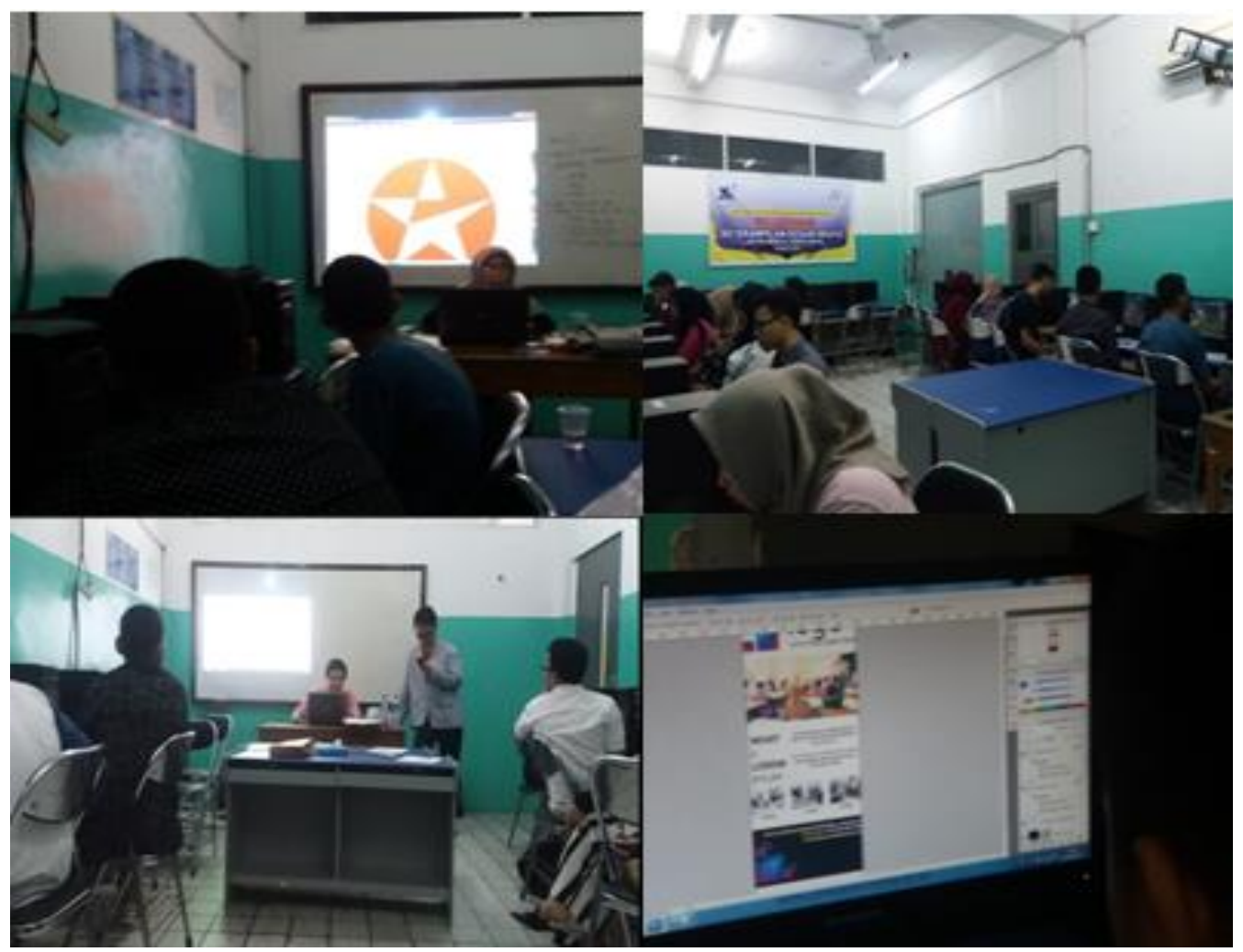

Gambar 2 Paraktek Materi CorelDraw dan Photoshop pembuatan Produk Advertising dan Reklame. 
DINAMISIA - Jurnal Pengabdian Kepada Masyarakat Vol. 3, No. 2 Desember 2019, Hal. 266-272

Pada gambar 2 memperlihatkan peserta diberikan materi tentang coreldraw dan photoshop untuk pembuatan banner. Peserta dengan antusias yang tinggi membuat produk advertising yaitu banner. Materi utama disajikan oleh Gustientiedina, M. Kom, Yenny Desnelita, M. Kom, Dr. Dewi Nasien, M.Sc, Wilda Susanti, M. Kom, Ramalia Noratama Putri, M. Kom dan dibantu oleh 2 orangu mahasiswa sebagai pendamping pembicara. Materi yang diberikan mulai dari pengenalan dasar sampai membuat banner, kartu undangan, famlet dan kartu nama menggunakan software coreldraw dan photoshop.

Untuk kegiatan pembuatan spanduk dan cara mencetak spanduk dilakukan pada percetakan Lunner Print milik alumni Perguruan Tinggi Pelita Indonesia, dimana langsung sebagai pembicara adalah pemilik percetakan tersebut yang sekaligus sebagai manager percetakan Lunner Print. Peserta disambut dengan baik oleh karyawan dan manager untuk melakukan pelatihan pembuatan spanduk dan langsung dipraktekan mencetak spanduk dengan mesin cetak yang dipunyai percetakan Lunner Print. Yang kegiatan pelatihannya dapat dilihat pada gambar 3 dibawah.

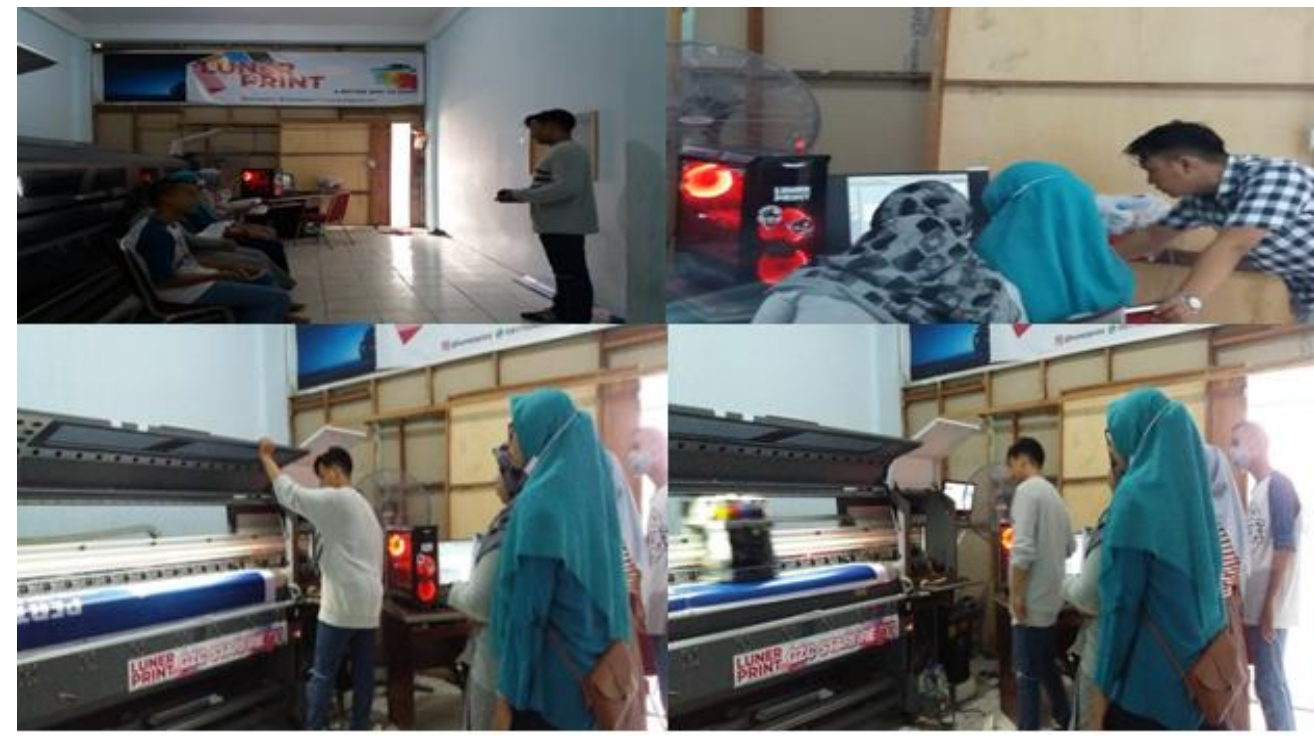

Gambar 3 Peserta Melakukan Kegiatan Pelatihan Pada Percetakan Lunner Print

Peserta PKMS diberikan materi cara membuat spanduk dan langsung cara mencetak spanduk oleh narasumber di percetakan Lunner Print yang dapat diilustrasikan pada gambar 3 diatas. Produk spanduk yang telah dirancang dan dibuat oleh peserta pelatihan dapat di lihat pada gambar 4 dibawah.

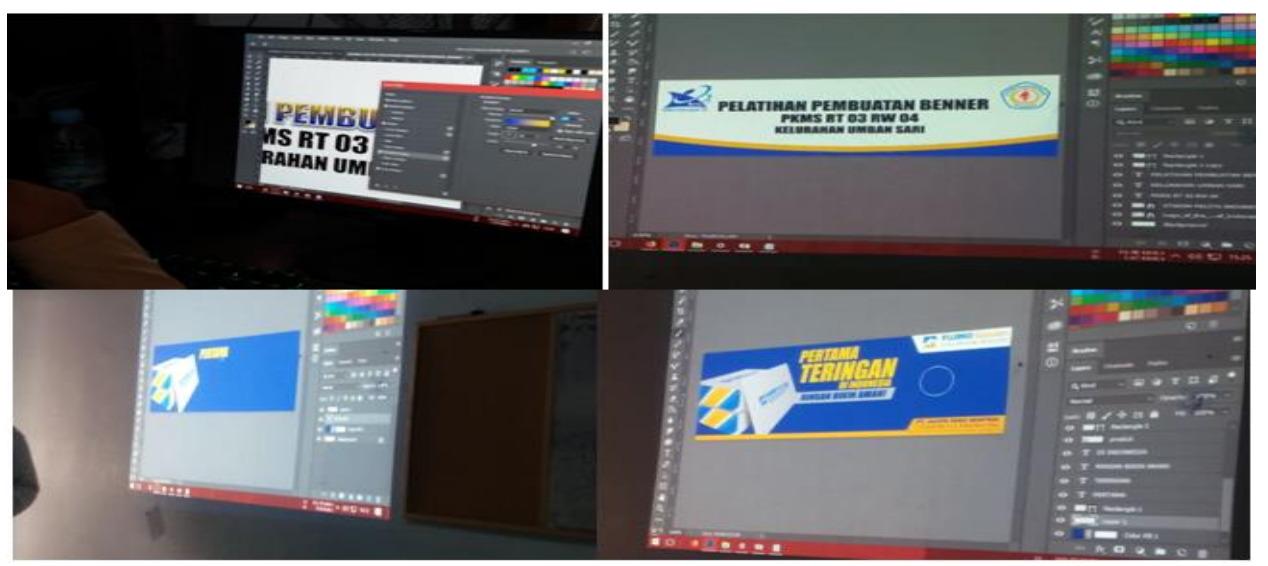

Gambar 4 Produk Spanduk Hasil Pelatihan Peserta PKMS Pada Percetakan Lunner Print

\subsection{Evaluasi Pelatihan Pembuatan Produk Advertising dan Reklame}

Setelah memberikan pelatihan kepada peserta yaitu pemuda dan pemudi dilingkungan RT03

RW04 Kel. Umban Sari Kec. Rumbai, selanjutnya untuk mengevaluasi keberhasilan pelatihan 
tersebut maka dilakukan penyebaran kuesioner kepada peserta pelatihan yang terlibat dalam PKMS ini dimana dari kusioner yang diisi peserta diperoleh hasil evaluasi sebagaimana yang tergambar pada tabel 1.

Tabel 1 Hasil Evaluasi Pelatihan Pembuatan Produk Advertising dan Reklame

\begin{tabular}{|c|c|c|c|}
\hline No & Pertanyaan & Rata-rata & Keterangan \\
\hline 1. & $\begin{array}{lll}\text { Kemudahan } & \text { dalam } & \text { penggunaan } \\
\text { softwarecoreldraw dan photoshop } & \\
\end{array}$ & 4.6 & Sangat Baik \\
\hline 2. & 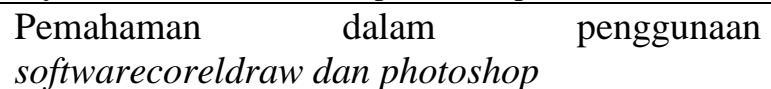 & 4.5 & Sangat Baik \\
\hline 3. & $\begin{array}{l}\text { Pemahaman dalam } \\
\text { advertising dan reklame }\end{array}$ & 4.6 & Sangat Baik \\
\hline 4. & $\begin{array}{l}\text { Kemudahan dalam penggunaan software } \\
\text { coreldraw dan photoshop untuk pembuatan } \\
\text { produk advertising dan reklame }\end{array}$ & 4.6 & Sangat Baik \\
\hline 5. & $\begin{array}{l}\text { Kemudahan dalam menggunakan mesin cetak } \\
\text { untuk produk advertising dan reklame }\end{array}$ & 4.4 & Sangat Baik \\
\hline 6. & $\begin{array}{l}\text { Pelatihan dapat diterima dengan baik oleh } \\
\text { seluruh peserta PKMS }\end{array}$ & 4.7 & Sangat Baik \\
\hline & Rata-rata & 4.57 & Sangat Baik \\
\hline
\end{tabular}

Dari data kusioner hasil evaluasi di atas dapat dilihat bahwa rata-rata respon peserta dalam pemahamannya serta manfaat dari pelatihan desain grafis menggunakan software coreldraw dan photoshop ini adalah sangat baik yang artinya perancangan desain grafis menggunakan software coreldraw dan photoshop untuk pembuatan produk-produk advertising dan reklame di implementasi dengan baik bagi peserta dalam mendapatkan bekal keterampilan dibidang desain grafis khususnya dengan coreldraw dan photoshop untuk dapat berwirausaha sendiri dan memenuhi kebutuhan lapangan kerja.

\section{KESIMPULAN}

Dari kegiatan pengabdian (PKMS) yang telah dilaksanakan, dapat disimpulkan sebagai berikut:

1. Peserta telah memahami software coreldraw dan photoshop untuk membuat produk advertising dan reklame.

2. Peserta telah dapat mempraktekan pembuatan banner, spanduk, kartu undangan dan advertising lainnya dengan mengunakan coreldraw dan photoshop.

3. Peserta sudah dapat mempraktekan cetak spanduk pada mesin percetakan di percetakan Lunner Print.

\section{SARAN}

Setelah dilakukan pelatihan desain grafis menggunakan software coreldraw dan photoshop diharapkan peserta dapat mempelajari dan melatih ulang mengenai materi yang telah diberikan agar dapat lebih kreatif didalam membuat produk-produk advertising dan reklame, dimana setelah mendapatkan pelatihan ini hendaknya dapat membuka usaha atau berwirausaha dibidang advertising dan reklame (percetakan).

\section{UCAPAN TERIMAKASIH}

Ketua dan Anggota PKMS mengucapkan terimakasih kepada Direktorat dan Pengabdian Masyarakat (DRPM) Kemenristekdikti sebagai pemberi dana untuk kelancaran kegiatan pengabdian ini dan Sekolah Tinggi Ilmu Komputer Pelita Indonesia, RT 03 RW 04 Kelurahan 
DINAMISIA - Jurnal Pengabdian Kepada Masyarakat Vol. 3, No. 2 Desember 2019, Hal. 266-272

Umban Sari sebagai Mitra serta Percetakan Lunner Print yang telah ikut berpartisipasi pada kegiatan PKMS ini.

\section{DAFTAR PUSTAKA}

[1] Adityawan. S. A, Tinjauan Desain Grafis. PT. Concept Media, Jakarta. 2010.

[2] Dameria. A, Panduan Dasar Warna Untuk Desain. PT. Gramedia Pustaka Utama. Jakarta, 2014.

[3] I. Afriliana and E. Budihartono, "Peningkatan Ketrampilan Multimedia CorelDraw Di SMK Assalafiyah kota Tegal," J. Abdimas PHB, vol. 1, no. 1, pp. 55-61, 2018.

[4] Ernawati, "Batik Design Training Sebagai Upaya Pembekalan Soft Skill Di Bidang Desain Grafis Terhadap Siswa-Siswi Smk Negeri 5 Kota," J. Rekursif, vol. 3, no. 1, pp. 54-60, 2015.

[5] D. Tri, R. Graha, B. S. Waloejo, and A. D. Wicaksono, "Perencanaan strategis industri kreatif sektor desain grafis kota malang aktor pemerintah dinas perindustrian," vol. 8, no. 0341, 2016.

[6] A. Fuad, T. M. Darajat, F. Desain, K. Universitas, and E. Unggul, "Pengenalan Dan Pelatihan Fotografi Menggunakan Aplikasi Komputer Desain ( Adobe Photoshop Dan Coreldraw ) Untuk Bisnis Industri Kreatif," no. Reflective LM.

[7] L. Susanto, T.T., Kusnadi, E., Retno, "Penggunaan Spanduk dan Brosur Sebagai Bahan Penunjang Media Publikasi Kegiatan (Studi Pada Ibu-Ibu Pengurus Yayasan Uswatun Hasanah, Pancoran Mas Depok Jawa Barat)," J. Abdimas Bsi, vol. Vol. 1 No., no. 3, p. 577, 2018.

[8] A. Yunanto, "Strategi Perancangan Model Career Path Progression ( CPP ) Pengembangan Jenjang Karir Lulusan pada Program Studi Manajemen Universitas Jenderal Soedirman," no. September, pp. 1-12, 2018.

[9] T. A. Shindina, "Interaktivnye tekhnologii obrazovaniya [Interactive technologies in teaching activities: educational guidance].South-Ural State University press," vol. 289, 2015.

[10] J. Archbold, "Why mentoring matters: what should you be looking for in a mentor? http://www.hr.com/en/magazines/leadership_excellence_essentials/february_2015_leadership/ why-mentoring-matters_i5nj5ra6.html.," 2015.

[11] K. N. W. Setyorini, Arifin. J, "Workshop Desain Brosur Sekolah SMK Mahardika Berbasis BitMap," J-ABDIPAMAS, vol. 1, p. 1, 2017.

[12] S. Rustan, Mendesain Logo. Jakarta.: Gramedia Pustaka., 2011. 